\title{
AHLU RIWAYAH DAN AHLU RA'Y
}

\author{
Oleh: Drs. Randi Makatungkang, M.HI
}

\begin{abstract}
ABSTRAK
Riwayat adalah sesuatu yang membahas tentang periwayatan segala sesuatu yang disandarkan pada nabi berupa perkataan, perbuatan, ketetapan atau pengakuan sifat jasmani atau tingkah laku dengan cara yang teliti dan terperinci. Ahlu riwayah selalu melihat dari segi sebab turunya serta periwayatan dan mereka memilih mana periwayatan yang terkuat sampai turunnya ayat tersebut. Ahlu riwayah didalam mengistimbatkan hukum sangat terikat dengan bunyi nas, tampak mencari alat hukumnya. Ahlu ra'yi selalu mengutamakan akal dan giat mengadakan tinjauan terliadap maksud syara yang terdapat dalam Al Quran. Alilu ra'yi mengusahakan agar supaya hukum syara dapat dimengerti maksudnya dan ditegakkan atas dasar yang sama dan tujuan yang sama yaitu kemaslahatan orang banyak.
\end{abstract}




\section{Pendahuluan}

Pada masa pertumbuhan dan pembinaan hukum Islam pada masa Rasul telah meninggalkan nas nas hukum baik yang berupa ayat Al Quran maupun hadis Nabi. Akana tetapi tidak semua orang Islam dapat mempelajari dan memahami nas nas hukum tersebut. Sebab banyak' diantara mereka adalah orang-orang awarnt yang tidak dapat memahami kecuali dengan bantuan orang yang dapat menjelaskannya.

Disamping nas nas hukum belum tersebar luas dikalangan kaum muslim karena Al Quran pada awal periode masih berupa lembaran lembaran tertentu yang disimpan di rumah Rasul dan beberapa orang sahabat sedangkan hadis sama sekali belum dibukukan.

Setelah bertambah luas daerah kekuasaan Islam pada periode banyak persoalan hukum yang muncul. Hal ini dikarenakan kaum muslimin yang menjadi penduduk daerah baru telah_ mempunyai tata cara dan adat istiadat sendiri sendiri sebelum agama Islam. Sehingga setelah $\mathrm{k}_{\mathrm{k}}$ mereka beragama Islam sering terdapat peristiwa-peristiwa yang belum pernah terjadi pada masa Rasul dan tidak didapatkan hukumnya dalam Al Quran dan hadis.

Dengan berbagai faktor diatas maka para sahabat merasa berkewajiban untuk memberi penjelasan dan penafsiran terhadap nas nas hukum baik dalam Al Quran maupun dalam hadis serta memberi terhadap persoalan persoalan hukum yang timbul dikalangan kaum muslimin. Mereka telah menggantikan kedudukan Rasul sehagai tempat kembali kaum muslim dalam urusan urusan yang berhubungan dengan hukum. Hal ini berarti kekuasaan penetapan hukum dalam arti memberi penafsiran dan fate dipegang oleh para ulama.

Kekuasaan ini mereka peroleh bukan dari petunjuk seorang khalifah atau pilihan umat, akan tetapi diperoleh hasil pergaulan mereka dengan Rasulallah yang cukup lama. Hafalan mereka terhadap avat ayat Al Quran dan hadis dan pengetahuan mereka tentang sebab sebab turunnya avat serta sebab-sebab adanva hadis hahkan diantara mereka ada yang diminta pertimbangan oleh Rasulallab dalam melakukan ljtihad.

Terjadinya perbedaan didalam menafsirkan dan memahami Al Quran serta menghilangkan kesulitan yang ditimbulkannya perlu kita ketahui sebabsebab turunnya ayat dan ini merupakan sebaik-baiknya jalan untuk memahami Al Quran. Ibnu Daqiqi 
Aidi mengatakan keterangan yang diperoleh dari asbabul nuzul adalah suatu metode yang kuat dalam memahami pengertian Al Quran. Wahidi mengatakan tidak mungkin memahami tafsir avat tanpa melihat kisah dan keterangan sekitar turunnya ayat.'

Persoalan inilah yang menyehahkan sampai terjadinya perbedaan didalam menafsirkan ayat-ayat para ahlu riwayah dan ahlu ra'yi. Ahli riwayah mengedepankan penafsiran lewat riwayat riwayat sedangkan ahlu ra'yi mengedepankan penafsiran ra'yu dan akal.

Dengan berbagai persoalan, tersebut maka penulis mengambil permasalahan sebagai berikut :

1. Apa yan dimaksud dengan ahlu riwayah dan ahlu ra'yi?

2. Apa yang menyebabkan terjadinya perhedaan penafsiran antara ahlu riwayah dan ahlu ra'yi?

\section{A. Ahlu Riwayah dan Ahlu Rayi}

a. . Ahlu riwayah

Ahlu riwayah dalam menafsirkan ayat dalam Al-Quran selalu mengedepankan sebab sebab turunnya ayat oleh riwayat yang shahih, yang satu lebih kuat dart yang lainnya atau sama. sama kuat. Apabila banyak riwayat yang, menerangkan sebab turunya ayat maka yang dipeuanui oleh ahli riwayat ialah yang shahih. Umpamanya riwayat yang shahih Jundab Al Bajili menceritakan pernah Rasul merasa sakit selama dua atau luta malam tiba-tiba datanglah kepada beliau seoranu anita mengatakan ya Muhammad sesunuguhnya saya mengharapkan agar syetanmu meninggalkan kamu lalu turunlah ayat Ad-dhuha satu sampai tiga sebagai berikut :

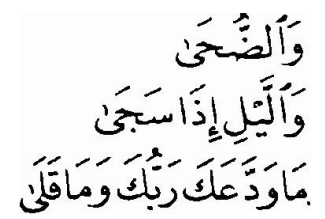

Demi waktu, demi malam bila is gelap Tuhanmu tidak meninggalkan kamu dan tidak pula membencimu.

Riwayat tersebut terdapat pada shahih Al Bukhari dan muslim dengan demikian lebih rajih atau lebih kuat dari yang lainnya.

Riwayah dan dhaif atau yang lemah Tibrani dan Ibnu Syaibah meriwayatkan dari hafsah dari masyara, dari ibunya, dari saudara perempuannya yang pernah menjadi pembantu Rasulallah, pernah seekor jarwan anak anjing senga atau binatang buas masuk 
rumah Rasul dia masuk dibawah dipan dan mati, sesudah itu beberapa hari maka wahyu tidak turun kepada beliau, lalu beliau tanya kepada khaula saudara khadijah apa yang terjadi dirumah Rasul karena jibril tidak datang kepada beliau. Saya bersihkan dan saya sapu bagian tempat tidurnya ada jarwah lalu saya buang jarwah yang sudah mati.

Setelah Rasulallah datang maka kelihatan janggut beliau bergerak-gerak setelah beliau turun kepadanya, maka beliau menjadi bergetar lalu Allah menurunkan surat Ad-dhuha yang berbunyi Wadhuha wallaili. Riwayat ini didhaifkan oleh Ibnu Hajar dalam buku Al Fathu karena didalam sanadnya ada yang tidak kena.

Adapun kisah terlambatnya jibril disebabkan kerena jarwah itu adalah masyhur. Bila diperhatikan jadinya itu dari segi akidah Islam yang diyakini selama ini maka malaikat tidak pernah mendurhaka dan senantiasa melaksanakan apa yang diperintahkan atasannya. ${ }^{3}$

Maka pendapat yang mengatakan bahwa terlambat datang wahyu kepada Rasulallah selama dua atau tiga hari tidak dapat diterima dan sifatnya hanya kebetulan saja, Allah hanya menguji kecintaan Beliau kepada wahyu agar beliau makin asyik kepada wahyu yang baru.

Apabila beberapa riwayat sama shahih tapi yang satu lebih kuat dari lainnya seperti riwayat shahih Bukhari dan Ibnu Masud meriwayatkan pada waktu saya bersama Nabi dalam suatu' kebun dan beliau sedang bertelekan diatas sebuah telapah kurrna tiba-tiba lewatlah ditempat itu rombongan orang yahudi sehagian mereka mengatakan kepada yang lain tanyakanlah kepadanya Muhammad mengenai ruh mereka tanyakan tapi beliau tidak menjawab saya kira bahwa beliau sedang menerima wahyu saya' berdiri saja ditempat itu kemudian turun wahyu surat al lsra'85

Dan mereka bertanya kepadamu tentane roh. Katakanlah : "Roh itu termasuk' urusan Tuhan-ku, dan tidaklah kamu diberi pengetahuan melainkan sedikit". ${ }^{4}$ Termizi meriwayatkan dalam shahihnya "Dari Ibnu Abbas bahwa yang menceritakan orang qurais menanyakan kepada orang yahudi" berikanlah kami pertanyaan kepadanya (Muhammad) jawab mereka tanyakan kepadanya mengenai ruh orang quraisy tanyakan kepada Rasul lalu turunkan wahyu al Isra. ${ }^{5}$ tarjih menguatkan :

Para ulama menguatkan riwayat Ibnu Masud diatas kerena hadir ditengah kisah itu.

Bila riwayat-riwayat samat nilainya dan waktu terjadinya berdekatan maka bila mungkin dijaman riwayat Bukhari yaitu pada waktu Hilal bin Umayah menuduh isterinya berzina dengan syarik didepan nabi Muhammad SAW maka beliau mengatakan kepada mereka, mengemukakan keterangan atau menyediakan punggungmu untuk menerima 
had zina, dia menjawab Demi Allah yang telah mengutus engkau, balm a aku adalah orang benar Turunlah jibril as membawa wahyu yaitu : Dan orang-orang yang menuduh isterinya (berzina), padahal mereka tidak ada mempunyai saksi-saksi selain diri mereka sendiri, maka persaksian orang itu ialah empat kali bersumpah dengan nama Allah, sesungguhnya dia adalah termasuk orang-orang yang benar.

Dan (sumpah) yang kelima : bahwa la'nat Allah atasnya, jika dia termasuk orangorang yang berdusta. Isterinya itu dihindarkan dari hukuman oleh sumpahnya empat kali atas nama Allah sesungguhnya suaminya itu benarbenar termasuk orang-orang yang dusta. dan (sumpah) yang kelima : balm a la'nat Allah atasnya jika suaminya itu termasuk orang-orang yang benar.

Riwayat Bukhari dan muslim (syakhan) sahabat bin saat, bahwa Umwaimir datang kepada Ashin bin adi. Dia adalah tokoh adlan menanyakan bagaimana pendapatmu seorang laki-laki suami yang menemukan isterinya bersama dengan seorang laki-laki, apakah dia harus membunuhnya (laki-laki itu) atau mereka membunuhnya atau apa yang baik dilakukannya. ${ }^{7}$

Bila terdapat beberapa riwayat dalam mentarjih dan tidak mungkin menjamakannya karena berjauhan masanya dianggap kuat yang turunva berulang kali. Misalnya Firman Allah SWT (Q.S.An Nahal 126) Dan jika kamu memberikan balasan, maka balaslah dengan balasan yang sama dengan siksaan yang ditimpakan kepadamu. Akan tetapi jika kamu' bersabar. sesungguhnya itulah yang lebih' balk bagi orangorang yang sabar. (Q.S.An Nahal 126).'

Baihakqi meriwayatkan bahwa nabi berdiri untuk Hainzah, ketika dia gugur sahid (diperang uhud) dan buat perumpamaan lalu turun ayat tersebut. Termizi dan hakim meriwayatkan dari Ubai bin Kaab setelah berhenti perang uhud ternyata bahwa yang gugur dari orang-orang ansyar 64 orang, dari muhajirin 6 orang diantaranya mereka ialah Hamzah bin Abdul Muthalib atau paman Rasul SAW mereka adakan 
pebandingan daranya. Lalu orang ansyarmengatakan bila kami diberi bahaya oleh mereka seperti ini, niscaya kami akan mengadakan gantinya atas mereka.

Setelah terjadi futuh makkah maka Allah menurunkan surat An Nahal 126 tersebut. Riwayat ini menunjukkan balm a dia diturunkan di Mekkah pada hari futuh Mekkah dan jarak antara perang uhud dengan futuh Mekkah kira-kira sembilan tahun oleh sebab itu, maka diang.l.tap bahwa dia turun berulang kali.

\section{b. Ahlu Ra'yi}

Para ulama ahli ra'yi giat melaksanakan tinjauan terhadap maksud-maksud syara dan dasar-dasar yang digunakan untuk menetapkan hukum sehingga mereka.. sampai pada suatu pendapat bahwa hukum, svara dapat dimemzerti maksudnya dan ditegakan atas dasar yang sama serta tujuan yang sama yaitu untuk mewujudkan kemaslahatan orang banyak.

Karena satu hukum dengan hukum yang lain saling bersesuaian dan saling bertentangan, berdasarkan kepada pendapat ini mereka memahami nas menguatkan nas yang satu dengan yang lainnya. Jika kelihatan ada pertentangan dan menetapkan hukum yang tidak ada nasnya meskipun dalam penetapan hukum tersebut sampai memalingkan nas dalam arti yang dhahir.

Aliran ahlu ra'yi berkembang di daerah Irak hal ini disebabkan karena :

1. Pengaruh dari sahabat yang pertarna mengajarkan fikih di dacrah ini yaitu Abdulallah bin Masud termasuk antara para sahabat yang banyak melakukan ijtihad atau menggunakan ra'yi

2. Hadis dari fatwa sahabat yang terdapat di Irak tidak sebanyak di Hijaz. Di daerah Irak banyak terjadi peristiwa yang tidak didapati hukumnya dalam Al Qurari,

3. hadis dan fatwa sahabat karena adat istiadat dan hubungan hukum dalam lapangan keperdataan mereka banyak dipengaruhi oleh hukum persi yang belum dikenal oleh masyarakat daerah Hijaz.

4. Irak adalah pusat kegiatan politik dan tempat timbul serta berkembangnya golongan hawaris dan syiah, yang eksesnya timbul palsuan hadis di daerah ini. Oleh karena itu para ulama Irak lebih berhati-hati dalam menerima suatu periwayatan hadis, mereka mensyaratkan dengan telah terkenalnya hadis dikalangan ulama fikih. 
Tokoh-tokoh ulama ahlu ra'yi antara lain :

1. Al Qama Bin Qais an nakhii (W62 th)

2. Ibrahim Bin Yasid an yazici' nakhai (95 th)

\section{KESIMPULAN}

I. Riwayat adalah sesuatu yang membahas tentang periwayatan segala sesuatu yang disandarkan pada nabi berupa perkataan, perbuatan, ketetapan atau pengakuan sifat jasmani atau tingkah laku dengan cara yang teliti dan terperinci.

2. Ahlu riwayah selalu melihat dari segi sebab turunya serta periwayatan dan mereka memilih mana periwayatan yang terkuat sampai turunnya ayat tersebut.

3. Ahlu riwayahdidalam $\mathrm{k}_{\mathrm{k}}$ mengistimbatkan hukum sangat terikat dengan bunyi nas, tampak mencari alat hukumnya.

4. Ahlu ra'yi selalu mengutamakan akal dan giat mengadakan tinjauan terliadap maksud syara yang terdapat dalam Al Quran.

5 Alilu ra'yi mengusahakan agar supaya hukum syara dapat dimengerti maksudnya dan ditegakkan atas dasar yang sama dan tujuan yang sama yaitu kemaslahatan orang banyak.

6. Mereka memahami nas dan menguatkan nas yang sama periwayatan dengan yang lain sama kuatnya. Dengan yang lain jika. kelihatan ada pertentangan yang $g_{v}$ menetapkan hukum tidak ada nasnya. 


\section{CATATAN KAKI :}

1. Kahar_Masyhur, Pokok-pokok Ulumul Quran (Jakarta, Cet I Rineka Cipta, 1992. 11,92

2. Departemen Agama RI, .41 Ourcm Dan Terjemah, h. 170.

3. Kahar Mansur Pokok Pokok Humid Quran, op eit h, 97.

4. Kahar Mansyur Op. cit h, 98,

5. Kahar Mansyur Op. cit $h, 100$

6. Depag. Op cit H. 100

Jurnal Al-Syir'ah Vol. 1 No. 2 Juli-Desember 2003 